\title{
Polyetherimide-Modified High Performance Epoxy Resin
}

\author{
Jyongsik JANG and Weon LEE* \\ Department of Chemical Technology, Seoul National University, \\ Shinlimdong Kwanakgu, Seoul, Korea \\ * Samsung Chemical Technology Center. \\ Samsung General Chemical Co., Ltd., San 14 Nong Seo-Ri, Kihung-Eup, \\ Yong In-Gun, Kyung Ki-Do, Korea
}

(Received July 9, 1993)

\begin{abstract}
In order to improve the fracture toughness and mechanical properties of TGAP/DAP system, modified polyetherimide was incorporated in the tetrafunctional epoxy resin system. During the hydrolysis of polyetherimide, the formation of new carboxylic acid and amide increased gradually with increasing the hydrolysis time of neat polyetherimide. As the content of modified polyetherimide was increased up to $10 \mathrm{wt} \%$, the mechanical property of cured epoxy resin was significantly increased compared with that of the unmodified polyetherimide system. In TGAP/DAP/MPEI system, the number and size of dispersed phase within cured epoxy resin were gradually decreased with the increase of the hydrolysis time of polyetherimide. In addition, investigation of the relationship between the morphology and the mechanical properties was also undertaken in TGAP/DAP/MPEI system.

KEY WORDS Tetrafunctional Epoxy Resin / Polyetherimide / Hydrolysis /

Fracture Toughness / Flexural Strength / Flexural Modulus / Morphology /
\end{abstract}

High performance epoxy resins have been used for advanced composite matrix in aerospace/aircraft industries. ${ }^{1-5}$ In the past decade, TGDDM/DDS system has retained good mechanical properties and easy processibility. However, this resin has been shown poor hot/wet performance because of high moisture absorption. ${ }^{6-15}$

Recently, new tetrafunctional epoxy resin, which has low moisture gain and high glass transition temperature, has been developed by Shell Chemical Company. ${ }^{16-19}$ This new resin is $N, N, N^{\prime}, N^{\prime}$-tetraglycidyl- $\alpha, \alpha^{\prime}$-bis(4-aminophenyl)-p-diisopropylbenzene (EPON HPT Resin 1071, abbreviated to TGAP). In the previous study, we have carried out to characterize the cure process of this resin system by means of isothermal and dynamic differential scanning calorimetry (DSC) scan. ${ }^{20-23}$

Toughening studies of epoxy resins have been received much attention in the areas of fiber reinforced polymer composite and structural applications, since the toughened matertials have the improved impact strength and fracture toughness. In order to alleviate the brittlness of epoxy resin, rubber toughening techniques have been used for this goal during over thirty years. These studies mainly focused on the morphology and mechanical properties of cured epoxy resin containing reactive rubber. ${ }^{24-29}$ The variations on the extent of toughening with acrylonitrile content of carboxyl terminated butadiene rubber, the nature of different curing agent, the concentration of reactive rubber, and different cure conditions have been the important factors for epoxy modifications. ${ }^{30}$

In spite of toughness improvement of epoxy resin with the elastomeric modifiers, the reduced glass transition temperature, heat distortion temperature, tensile, and flexural modulus of modified epoxy system have limited 
various applications of modified epoxy resins. ${ }^{30}$

Recently, functional thermoplastic oligomers and high performance thermoplastics have been used for toughness improvement of epoxy resin and other thermosets. ${ }^{31-41}$ Bauer et al. reported that high performance epoxy resin was significantly improved at thermoplastic levels of $20-30 \%$ by weight. ${ }^{39}$ In addition, thermoplastic modified tetrafunctional epoxy resin showed good flexural strength and modulus. In this case, they directly used commercial thermoplastic modifiers for high performance epoxy resin without control of the interface between the dispersed phase and the cured epoxy resin.

Although the use of thermoplastic modifier has been important for the improvement of fracture toughness as well as the mechanical properties of high performance epoxy resin, these are very limited informations concerning the interfacial control between thermoplastic modifier and epoxy resin.

It is the purpose of this paper, therefore, to chemically modify the polyetherimide (PEI) in order to improve the fracture toughness of tetrafunctional epoxy resin and to characterize the thermoplastic modifier and cured epoxy resin. The present work is also an attempt to promote the mechanical properties and the hot/wet performance of cured tetrafunctional epoxy resin using pristine and chemically modified PEI.

In addition, this paper is also concerned with the relationship between the mechanical properties and the morphology of TGAP/ DAP/MPEI system.

\section{EXPERIMENTAL}

\section{Materials}

The epoxy resin used in this study was TGAP reșin supplied by Shell Chemical Company. This resin was technical grade of $N, N, N^{\prime}, N^{\prime}$ tetraglycidyl- $\alpha, \alpha^{\prime}$-bis(4-aminophenyl)- $p$-diisopropylbenzene (epoxy equivalent weight: $\left.166 \mathrm{~g} \mathrm{~mol}^{-1}\right)$.

The curing agent was $\alpha, \alpha^{\prime}$-bis(3,5-dimethyl4-aminophenyl)-p-diisopropylbenzene, (EPON HPT 1062, abbreviated to DAP) also supplied by Shell Chemical Company. These materials were used as supplied without further purification. The structures of TGAP resin and DAP curing agent were illustrated in Figure 1.

PEI (ULTEM 1000) supplied by the General Electric Co. was used as thermoplastic modifier. The number average molecular weight $\left(M_{n}\right)$ of PEI was 20000 . Its structural formula was also represented by Figure 1 . In addition, Table I represents the physical properties of
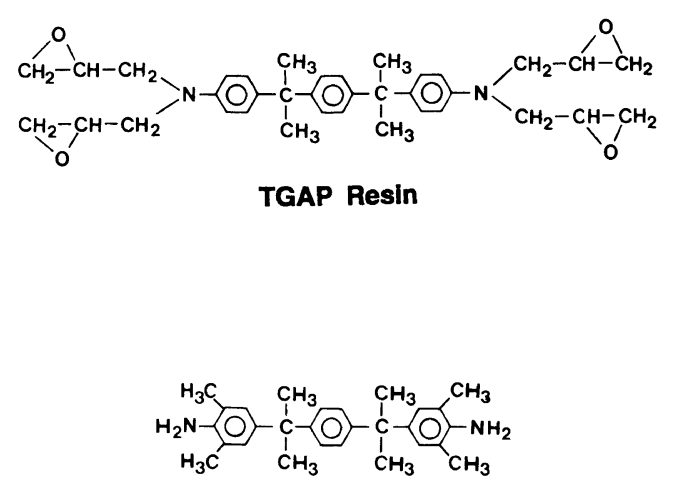

DAP Curing Agent

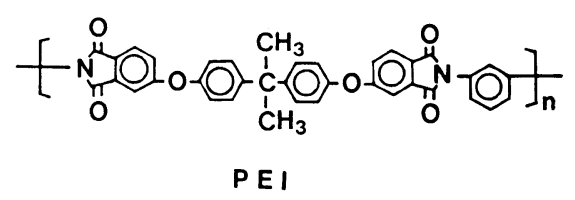

Figure 1. The structures of TGAP resin, DAP curing agent and PEI.

Table I. Typical properties of polyetherimide ${ }^{\mathrm{a}}$ at room temperature

\begin{tabular}{lc}
\hline Molecular weight $\left(M_{n}\right)$ & 20000 \\
Tensile strength & $104.88 \mathrm{MPa}$ \\
Flexural strength & $150 \mathrm{MPa}$ \\
Flexural modulus & $3.4 \mathrm{GPa}$ \\
Fracture energy & $2.5 \mathrm{~kJ} \mathrm{~m}^{-2}$
\end{tabular}

a ULTEM 1000. 
PEI.

10 grams of PEI was dissolved in $200 \mathrm{ml}$ of methylene chloride/dioxane cosolvent and precipitated in $1000 \mathrm{ml}$ of $n$-hexane. This powder was dispersed in distilled water and maintained at $70^{\circ} \mathrm{C}$ with adding $1 N \mathrm{NaOH}$ solution. Modifed PEI was filtered and dried in vacuo at $80^{\circ} \mathrm{C}$.

\section{Experimental Methods}

Three sorts of tetrafunctional epoxy resin systems, that is, TGAP/DAP system, TGAP/ DAP/PEI system, and TGAP/DAP/modified PEI system were cured by melt casting.

In the case of TGAP/DAP system, molten resin was prepared at $170^{\circ} \mathrm{C}$ by mechanical stirrer, and subsequently, degassed in vacuum oven under $30 \mathrm{mmHg}$ at $175^{\circ} \mathrm{C}$. This molten resin was poured in the aluminum casting molder and cured for 2 hours at $150^{\circ} \mathrm{C}$ and consecutively cured for 4 hours at $200^{\circ} \mathrm{C}$.

Melt casting specimens of TGAP/DAP/PEI system were obtained by dissolving TGAP resin and PEI in methylene chloride, followed by removing the solvent under the vacuum of $100 \mathrm{mmHg}$ at $190^{\circ} \mathrm{C}$.

DAP curing agent and TGAP/PEI mixture were melted separately at $180^{\circ} \mathrm{C}$ and mixed thoroughly by mechanical stirrer, degassed in a vacuum oven at $190^{\circ} \mathrm{C}$. All the test specimens were cast and cured by the same method of TGAP/DAP system.

In the case of TGAP/DAP/modified PEI system, TGAP resin and modified PEI were dissolved in dimethyl formamide, and subsequently, removing the solvent under the vacuum of $100 \mathrm{mmHg}$ at $170^{\circ} \mathrm{C}$. Molten DAP curing agent was added in TGAP/modified PEI mixture and mixed by mechanical stirrer. Following procedure was same as TGAP/ DAP/PEI system.

\section{Measurements}

A Fourier transform infrared spectrophotometer (Digilab FTS-80E) with a liquid nitrogen cooled MCT detector was used at a reso- lution of $4 \mathrm{~cm}^{-1}$ with coaddition of 128 scans. $\mathrm{KBr}$ pellet method was used for the analysis of PEI and the spectrophotometer was purged with dry air to remove the atmospheric moisture.

The calorimetric measurement was conducted using a Perkin-Elmer 4 differential scanning calorimeter with microprocess controller. The temperature and powder calibration of the DSC were optimized for the temperature range of $20-300^{\circ} \mathrm{C}$ by using high purity indium as the DSC standard calibration.

Flexural properties of the cured epoxy specimens were measured by three-point bending test (ASTM D790) using an Universal Testing Machine model Instron 1123. The crosshead speed was $10 \mathrm{~mm} \mathrm{~min}^{-1}$. The gauge length was $50 \mathrm{~mm}$. In a fracture test, rectangular compact tension specimens were prepared by ASTM STP $381 . .^{42}$ The crosshead speed was $1.0 \mathrm{~mm} \mathrm{~min}^{-1}$ and 7 specimens were tested for this study.

Modified PEI was dissolved in dimethyl formamide and viscosity measurement of modified PEI was carried out by Ubbelohde viscometer.

For the morphological study of cured epoxy resin, scanning electron microscope (SEM Model JSM-35CF, JEOL) was used. The accelerating power was $15 \mathrm{kV}$ and fractured surface was coated with $300 \AA$ thickness of gold by ion sputtering.

\section{RESULTS AND DISCUSSION}

\section{Chemical modification of PEI}

PEI powder was hydrolyzed by sodium hydroxide solution at $70^{\circ} \mathrm{C}$ in order to introduce new functional groups at the backbone of PEI reacting with high performance epoxy resin during curing. Hydrolysis times of polyetherimide were $30 \mathrm{~min}, 90 \mathrm{~min}$, and $180 \mathrm{~min}$ respectively, which were called MPEI-30, MPEI-90, and MPEI-180. Untreated PEI was abbreviated to UPEI in this study. 


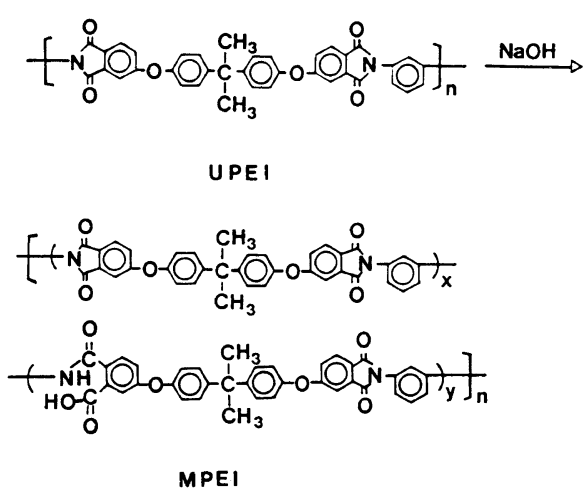

Figure 2. Expected schematic diagram of PEI hyrolysis.

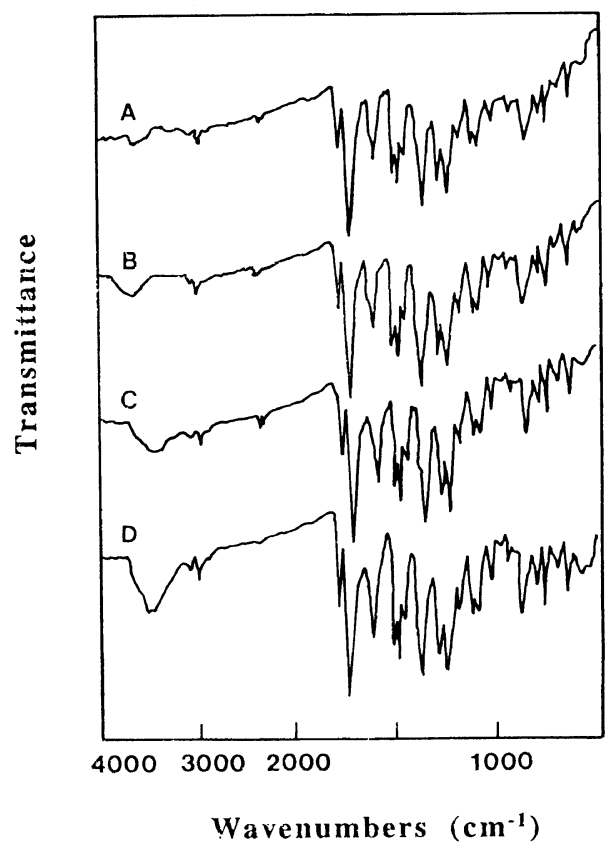

Figure 3. Transmission spectra of hydrolyzed PEI as a function of different hydrolysis time: A, UPEI (untreated); B, MPEI-30 (30 min); C, MPEI-90 (90 min); D, MPEI-180 (180 min).

Expected schematic diagram of PEI hydrolysis was shown by Figure 2. After the hydrolysis of PEI, new functional groups, which were amide and carboxylic acid, might be formed at the backbone of PEI. These new functional groups were characterized by Fourier transform infrared spectroscopy (FTIR).
Table II. The limiting viscosity numbers of UPEI and MPEI

\begin{tabular}{ccccc}
\hline & UPEI & MPEI-30 & MPEI-90 & MPEI-180 \\
\hline $\begin{array}{c}\text { Limiting } \\
\text { viscosity } \\
\text { number }\end{array}$ & 0.262 & 0.262 & 0.264 & 0.267 \\
\hline
\end{tabular}

Figure 3 represents the transmission spectra of hydrolyzed PEI as a function of different hyrolysis times. In the case of UPEI (Figure $3 \mathrm{~A})$, the band at $1240 \mathrm{~cm}^{-1}$ is attributed to $\mathrm{C}-\mathrm{O}$ stretching mode and the peak at $1280 \mathrm{~cm}^{-1}$ results from aromatic $\mathrm{C}-\mathrm{N}$ vibration mode. The stretching mode of $\mathrm{CO}-\mathrm{N}-\mathrm{CO}$ groups appears at $1730 \mathrm{~cm}^{-1}$ and the peaks at $1365 \mathrm{~cm}^{-1}$ and $1450 \mathrm{~cm}^{-1}$ are assigned to $\mathrm{C}-\left(\mathrm{CH}_{3}\right)_{2}$ group and $\mathrm{C}-\mathrm{CH}_{3}$ group, respectively.

As the hydrolysis time of PEI increased from $30 \mathrm{~min}$ to $180 \mathrm{~min}$ (Figure $3 \mathrm{~B}-\mathrm{D}$ ), new broad band at $3600-3200 \mathrm{~cm}^{-1}$ region appears due to $\mathrm{OH}$ stretching mode of new functional carboxylic acid. This is because carboxylic acid forms via the chain scission of PEI imide ring during the hydrolysis of UPEI. New formed amide also appears at $3600-3200 \mathrm{~cm}^{-1}$ region and it is difficult to distinguish from $\mathrm{OH}$ stretching peak due to the overlap between both peaks. In addition, the absorbance at $1240 \mathrm{~cm}^{-1}$, which originates from C-O stretching mode, was gradually increased with increasing the hydrolysis time of PEI. Considering the spectrum analysis, it confirms that new carboxylic acid and amide forms at the backbone of PEI during the hydrolysis reaction and the amount of functional groups increases with increasing PEI hydrolysis time.

Table II illustrates the limiting viscosity numbers of pristine and hydrolyzed PEIs. From the table, the limiting viscosity number of untreated PEI is 0.262 . Compared to the pristine PEI, the limiting viscosities of modified PEIs show the similar values. These values do not depend on the hydrolysis time of PEI. 


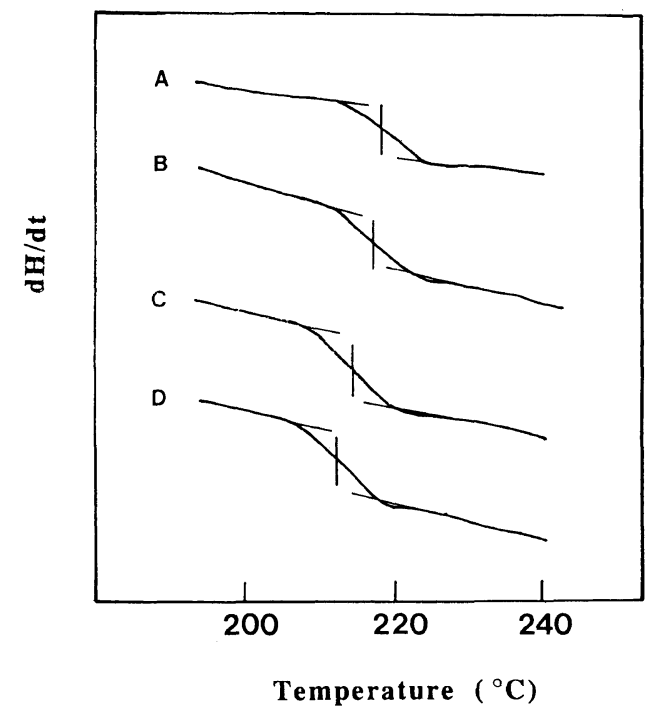

Figure 4. DSC scans at heating rate of $10^{\circ} \mathrm{Cmin}^{-1}$ for UPEI (A), MPEI-30 (B), MPEI-90 (C), and MPEI-180(D).

Judging from these data, it can be concluded that hydrolysis of PEI does not affect the complete scission of main chains of PEI. It means that partial ring opening of imide group occurs during the hydrolysis of PEI. This phenomenon represents that the $\mathrm{NaOH}$ solution treatment does not affect the mechanical properties of pristine PEI. This result can be also validated by thermal analysis of PEI.

Figure 4 shows the DSC thermograms of pristine and hydrolyzed PEI at different treatment times. As the treatment time of hydrolysis increases up to $180 \mathrm{~min}$, glass transition temperature of PEI decreases a very small amount compared to that of pristine PEI. These phenomena also confirm that the main chain scission of PEI does not occur during the hydrolysis of PEI.

New carboxylic acid and amide groups might react with tetrafunctional epoxy during curing reaction and expected reaction schemes are as follows:<smiles>[R]N=CC1OC1[R]</smiles>

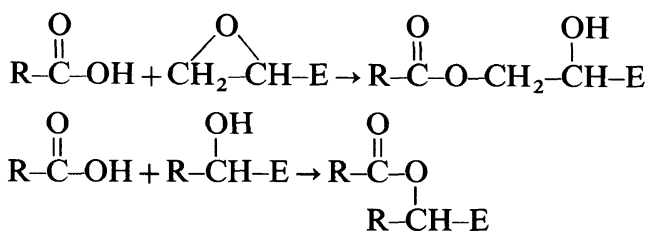

Equation 1 represents the epoxide reaction with amide of PEI and eq 2 and 3 show the esterification of carboxylic acid within epoxide groups.

In order to ascertain whether new functional groups of PEI react with epoxy resin, the dynamic experiments of TGAP/DAP/MPEI30,90 , and 180 were carried out at heating rate of $10^{\circ} \mathrm{C} \mathrm{min}{ }^{-1}$. At that time, the concentration of MPEI was fixed at $5 \%$ by weight of TGAP/DAP/MPEI system.

Although there is no exothermic peak in TGAP/DAP/UPEI system, new exothermic peak at $173^{\circ} \mathrm{C}$ appears in TGAP/DAP/MPEI system due to the chemical reaction of new functional group with epoxy resin. As the hydrolysis time of PEI increases from $30 \mathrm{~min}$ to $180 \mathrm{~min}$, the area of exothermic peak increases gradually; $0.17 \mathrm{cal} \mathrm{g}^{-1}$ (TGAP/DAP/ MPEI-30), $0.77 \mathrm{cal} \mathrm{g}^{-1}$ (TGAP/DAP/MPEI90), and $0.84 \mathrm{cal} \mathrm{g}^{-1}$ (TGAP/DAP/MPEI180). From these results, it can be concluded that new functional groups of PEI react with epoxy resin during curing reaction.

\section{Mechanical Properties}

Mechanical properties of epoxy resins are changed by the addition of thermoplastic modifiers. Especially, the fracture properties of cured epoxy resins are dramatically affected and become different from those of the unmodified epoxy. The compact tension specimen is currently recommended for the determination of the fracture energy of epoxy resins. This type of specimen is to be deformed under a bending moment, that is, subjected to a point loading through pins placed below and above the crack surface. If a compact tension test is performed, the fracture energy may be calculated by: 


$$
K_{\mathrm{IC}}=\frac{P_{c} Y a^{1 / 2}}{B W}
$$

The recommended design of compact tension rectangular specimen is shown in Figure 5.

Figure 6 shows the fracture toughness of cured epoxy resion as a function of UPEI. As the concentration of UPEI increases up to $10 \%$ by weight, the fracture energy of epoxy resin increases linearly. Because UPEI does not have any reacting groups toward epoxy resin

A

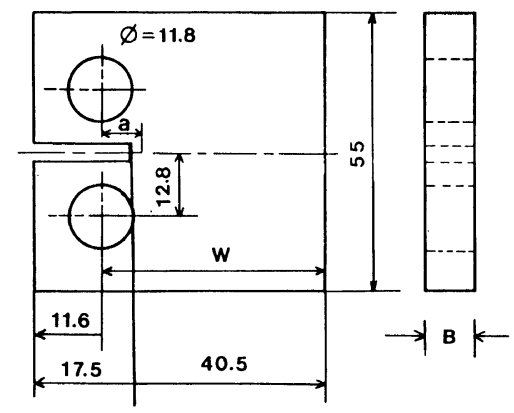

B
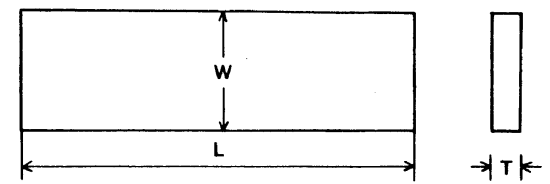

Figure 5. Compact tension rectangular specimen (A) for fracture toughness measurement and specimen (B) for flexural property.

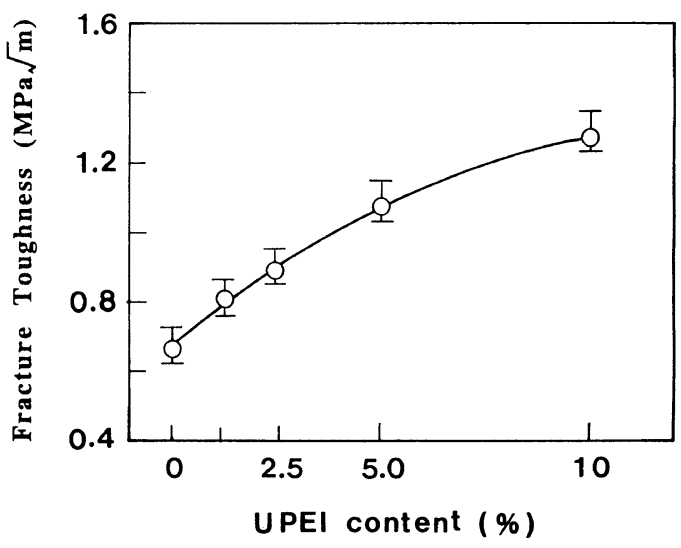

Figure 6. Fracture toughness as a function of UPEI content for TGAP/DAP/UPEI system. and has a nonpolar character, phase separation of UPEI/epoxy system occurs at the low concentration of UPEI during cure reaction. A small amount of UPEI added to the epoxy resin forms a dispersion of particles in the matrix. This particulate dispersion is mainly responsible for the toughening of the base resin. The effect of UPEI particle on fracture is to allow the energy to be dissipated into a relatively large volume of material at crack tip.

Figure 7 represents the dry and hot/wet flexural strength of UPEI/epoxy systems as a function of UPEI concentration. From the figure, flexural strengths of UPEI/epoxy systems increase with increasing the concentration of UPEI. This is reason because the flexural strength of UPEI is higher than that of epoxy resin. In general, the flexural strengths of elastomer modified epoxy resins decrease as the concentration of carboxyl terminated butadiene rubber increases in the cured epoxy resin. However, thermoplastic modified epoxy systems show the synergistic effect by PEI and epoxy resin.

Figure 8 shows the flexural modulus of UPEI/epoxy resin system. In this case, flexural modulus of UPEI/epoxy resin does not change by the addition of UPEI into epoxy resin. This result can be explained by the fact that flexural modulus of UPEI is similar to that of epoxy

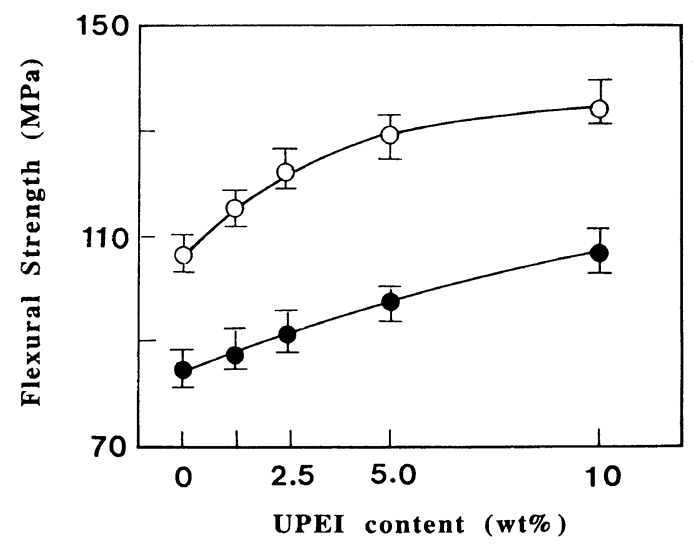

Figure 7. Flexural strength as a function of UPEI content for TGAP/DAP/UPEI system, dry $(O)$ and hot/wet (O). 


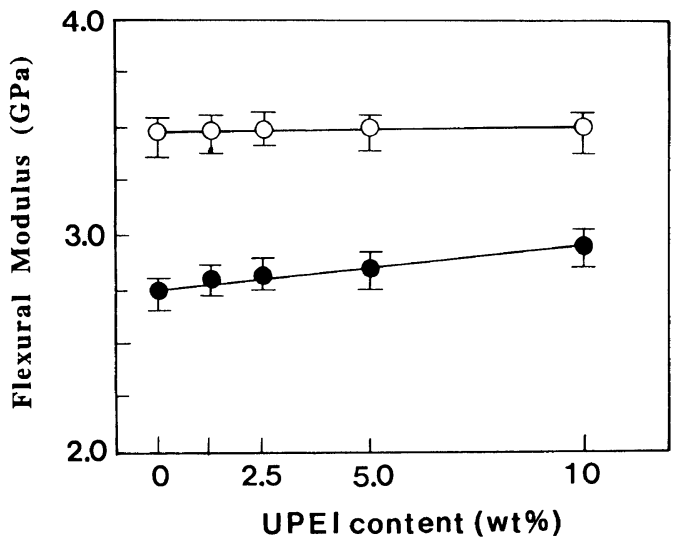

Figure 8. Flexural modulus as a function of UPEI content for TGAP/DAP/UPEI system, dry (O) and hot/wet (O).

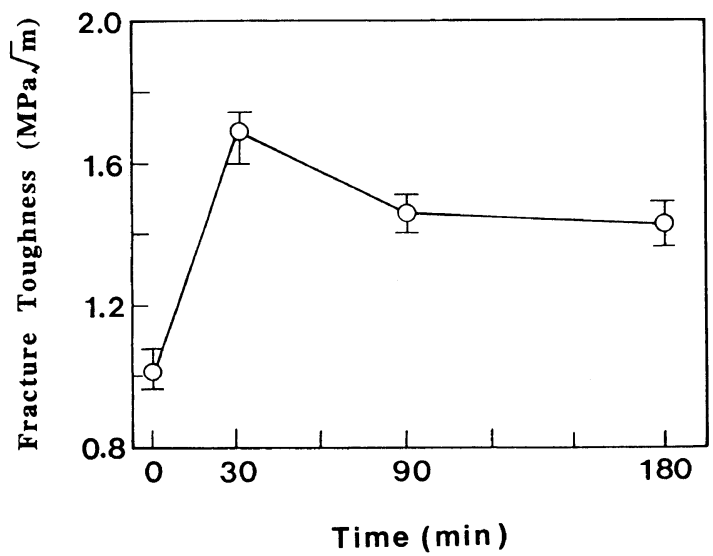

Figure 9. Fracture toughness of unmodified and modified PEI/epoxy systems as a function of PEI hydrolysis time (5wt $\%$ PEI content).

resin. However, hot/wet flexural modulus of UPEI/epoxy resin increases linearly as the concentration of UPEI increases up to $10 \%$ by weight due to the low moisture gain of UPEI.

Figure 9 represents the fracture toughness values of unmodified and modified PEI/epoxy systems as a function of PEI hydrolysis time. These values are generally used as a relative measure of the toughness of materials. Compared to the UPEI/epoxy system, fracture toughness of the MPEI/epoxy systems show the maximum value at 30 min of treatment time and gradually decreased with increasing the

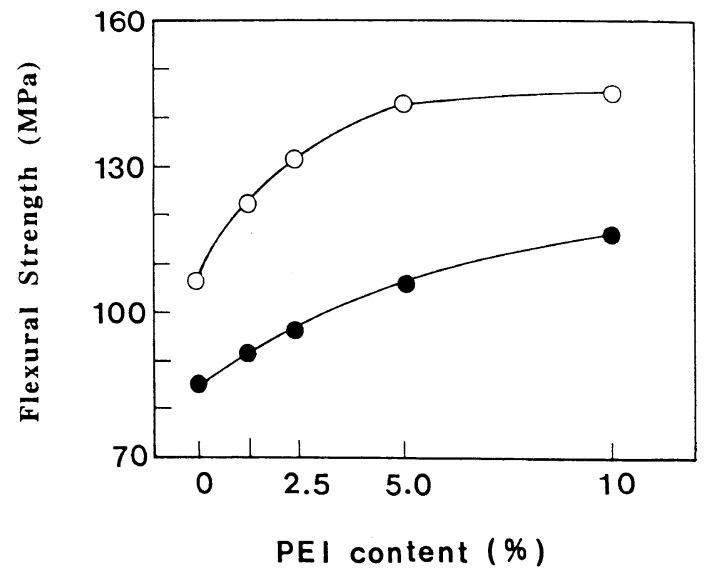

Figure 10. Flexural strength as a function of PEI content for TGAP/DAP/MPEI-30 system, dry (O), and hot/wet (O).

PEI treatment time up to $180 \mathrm{~min}$.

From the view point of hydrolysis, the degree of hydrolysis of PEI increases as the treatment time of PEI increases under the sodium hydroxide solution. New functional groups of carboxylic acid and amide form from the ring opening of imide moiety of PEI. The formation of PEI/epoxy adducts occurs during the curing followed by the reaction of these new functional groups toward epoxy resin. This phenomenon suppresses the phase separation of PEI/epoxy system and the dispersed phase of PEI forms at the later stage of epoxy cure. At the same concentration of hydrolyzed PEI within the epoxy resin, the amount of dispersed phase within the cured epoxy resin decreases with increasing the treatment time of PEI and the fracture thoughness of cured epoxy resin shows the maximum value at $30 \mathrm{~min}$ of treatment time and also decreased with increasing the PEI modification.

Figure 10 shows the dry and hot/wet flexural strengths of MPEI-30/epoxy systems. Compared to the previous figure, both dry and hot/wet, flexural strength of MPEI-30/epoxy systems increase drastically as the modified PEI content increases up to $10 \%$ by weight. PEI is more hydrophobic than epoxy resin and this phenomenon enhances with the increasing the 


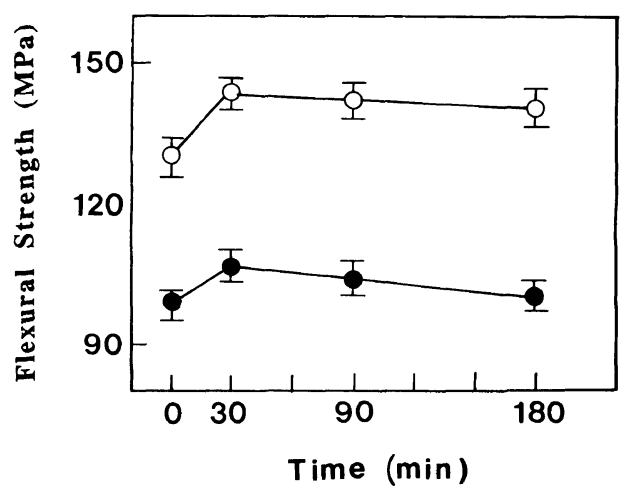

Figure 11. Flexural strength of unmodified and modified $\mathrm{PEI} /$ epoxy systems as a function of PEI hydrolysis time, dry (O) and hot/wet (O) (5 wt\% PEI content).

concentration of PEI within the epoxy resin. Judging from these data, it can be explained that the addition of modified PEI in the epoxy resin improves the dry flexural strength as well as the hot/wet performance of cured PEI/epoxy resin systems.

The hydrolysis effect of PEI as a function of treatment time is demonstrated by Figure 11. In this case, the content of PEI within the epoxy resin is $5 \%$ by weight. From this figure, the flexural strength of modified PEI/epoxy improves compared to the unmodified PEI/ epoxy and the maximum value occurs at $30 \mathrm{~min}$ of PEI treatment time. As the PEI treatment time increases up to $180 \mathrm{~min}$, the dry and hot/wet flexural strength slightly decreases compared to the maximum value of flexural strength. The more hydrolyzed PEI, the less hydrophobic character. This character reflects the decrease of flexural strength in cured PEI/epoxy system to some extent.

PEI content in the dispersed phase affects the mechanical property of modified PEI/epoxy system. This phenomenon can be also explained by the morphological aspect of fractured PEI/epoxy system at the later stage of this experiment.

Table III summarizes the dry and hot/wet flexural modulus and the fracture energy of PEI/epoxy system. From the table, flexural modulus of MPEI/epoxy system does not
Table III. Properties of PEI modified TGAP resin cured with DAP curing agent

\begin{tabular}{|c|c|c|c|c|}
\hline \multirow{2}{*}{$\begin{array}{l}\text { TGAP/DAP } \\
\text { PEI system }\end{array}$} & & \multicolumn{2}{|c|}{ Flexual modulus $(\mathrm{GPa})$} & \multirow{2}{*}{$\begin{array}{c}\begin{array}{c}\text { Fracture } \\
\text { energy }\end{array} \\
\mathrm{kJ} \mathrm{m}^{-1}\end{array}$} \\
\hline & & RT/Dry & Hot/Wet & \\
\hline UPEI & 0.0 & 3.41 & 2.88 & 0.077 \\
\hline \multirow[t]{4}{*}{$(w t \%)$} & 1.25 & 3.41 & 2.93 & 0.115 \\
\hline & 2.5 & 3.40 & 2.95 & 0.136 \\
\hline & 5.0 & 3.43 & 2.9 & 0.205 \\
\hline & 10.0 & 3.43 & 3.0 & 0.269 \\
\hline \multirow[t]{4}{*}{ MPEI-30 } & 1.25 & 3.44 & 2.95 & 0.257 \\
\hline & 2.5 & 3.42 & 2.99 & 0.371 \\
\hline & 5.0 & 3.47 & 3.07 & 0.489 \\
\hline & 10.0 & 3.45 & 3.06 & 0.545 \\
\hline \multirow[t]{4}{*}{ MPEI-90 } & 1.25 & 3.42 & 2.93 & 0.214 \\
\hline & 2.5 & 3.45 & 2.93 & 0.291 \\
\hline & 5.0 & 3.45 & 2.97 & 0.371 \\
\hline & 10.0 & 3.48 & 3.05 & 0.464 \\
\hline \multirow[t]{4}{*}{ MPEI-180 } & 1.25 & 3.44 & 2.90 & 0.207 \\
\hline & 2.5 & 3.44 & 2.92 & 0.257 \\
\hline & 5.0 & 3.48 & 3.02 & 0.349 \\
\hline & 10.0 & 3.50 & 3.10 & 0.408 \\
\hline
\end{tabular}

change drastically with variations of PEI concentrations and the modification time of PEI. However, flexural modulus of MPEI/ epoxy systems show relatively higher values compared to that of UPEI/epoxy system. The fracture energy reaches a maximum at $30 \mathrm{~min}$ of modification time, whereas the flexural modulus is highest at $180 \mathrm{~min}$. In the case of hot/wet condition, flexural modulus of MPEI/ epoxy system increases gradually with increasing the concentration of MPEI within the epoxy resin. Judging from these data, it can be concluded that chemical reaction between the epoxy resin and PEI particle as well as the reduction of moisture gain due to the introduction of PEI into the epoxy resin improve the flexural modulus of MPEI/epoxy systems.

\section{Morphological Consideraion}

With the added PEI particles, the mechanical properties of cured epoxy resin is closely related to the change in resin morphology. Figure 12 shows the fractured surface of UPEI/epoxy 


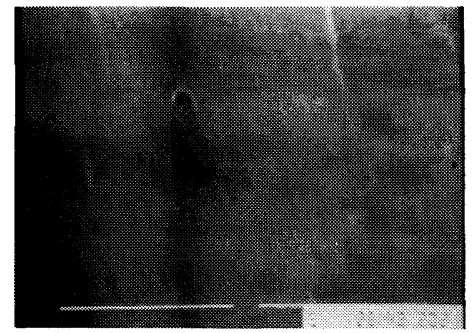

A

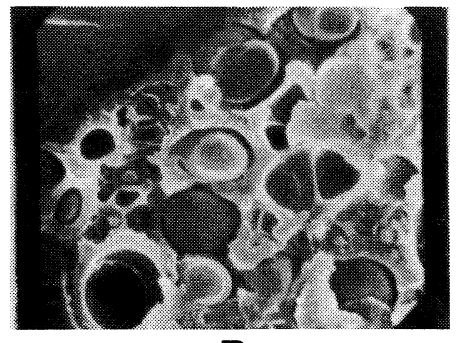

D

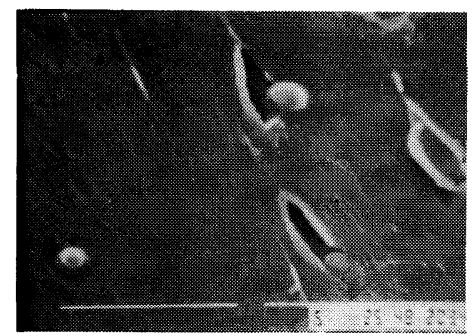

B

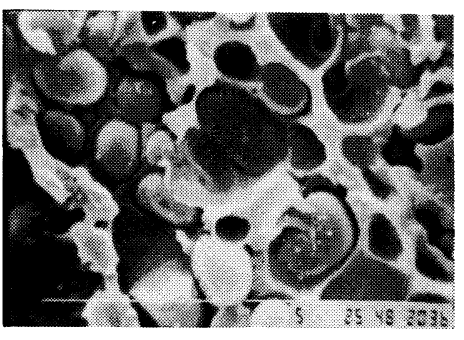

E

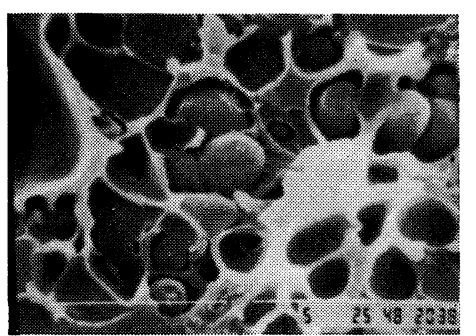

C

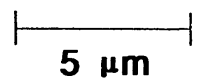

Figure 12. Scanning electron micrographs of TGAP/DAP/UPEI system as a function of UPEI concentration: (A) Control; (B) $1.25 \mathrm{wt} \%$; (C) $2.5 \mathrm{wt} \%$; (D) $5.0 \mathrm{wt} \%$; (E) $10.0 \mathrm{wt} \%$.

system under a scanning electron microscope. In the case of the control, no phase separation appears on the smooth fractured epoxy surface without the PEI particle. As the concentration of PEI increases, UPEI/epoxy system shows the roughness on the fractured surface gradually. Phase separation of cured UPEI/ epoxy system occurs at the low concentration of PEI mixed in the epoxy. This is because UPEI particles have poor compatibility with tetrafunctional epoxy resin during the curing. In the particulate region, the diameter and number of UPEI particle increase with increasing the concentration of UPEI in the epoxy resin. Fractured surface shows several holes and the voids between dispersed UPEI particles and continuous epoxy phase. These holes apparently resulted from the slippage of the dispersed particles formed in situ by the UPEI during curing. These phenomena are reasonable to expect that the boundary between the particle and matrix has poor interfacial adhesion and thus, under stress, has the absence of chemical and physical bonding at the interface. Large UPEI particles are shown to be embedded in the epoxy matrix, and the presence of large holes suggests that those particles served as a sort of nucleation site for local shear deformation, in many cases resulting in the particles being pulled out of the matrix.

As has been mentioned, small amount of PEI added to the epoxy resin forms a dispersion of small particles in the continuous phase and this particulate dispersion is mainly responsible for the toughening of the base resin. The principal effect of the PEI additive on fracture is to allow the energy to be dissipated into a relatively large volume of material under the external stress. As PEI concentration increases to $10 \%$ by weight or more, fracture energy of cured epoxy resin increases continuously. The toughening effect of PEI additive increases initially very rapidly with increasing PEI concentration. The fracture energy of the toughened epoxy leveled off to an asymptotic values. This phenomenon is related to the morphological change in cured epoxy resin.

Scanning electron micrographs of modified PEI/epoxy resin system are represented by 


\section{J. JANG and W. LEE}

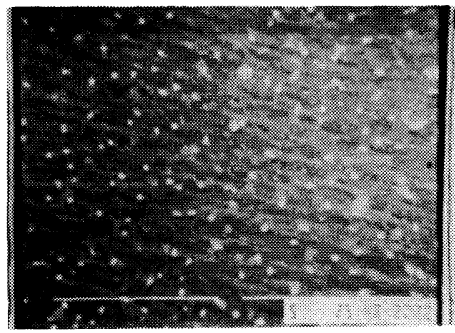

A

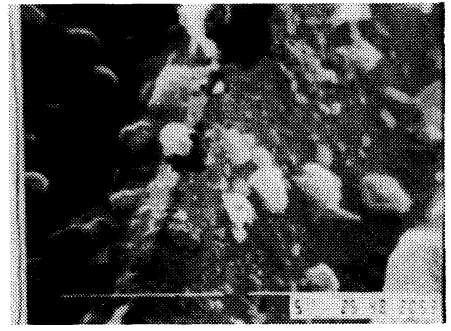

C

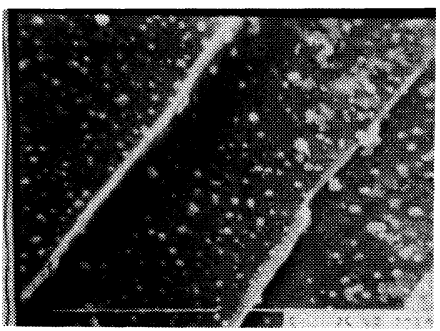

B

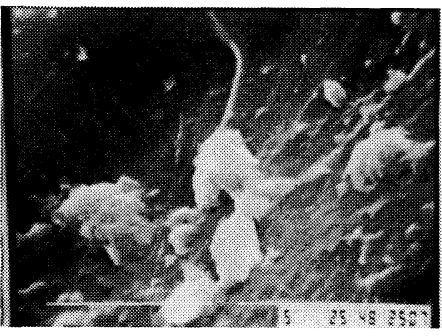

D
$5 \mu \mathrm{m}$

Figure 13. Scanning electron micrographs of TGAP/DAP/MPEI-30 system as a function of MPEI concentration: (A) $1.25 \mathrm{wt} \%$; (B) $2.5 \mathrm{wt} \%$; (C) $5.0 \mathrm{wt} \%$; (D) $10.0 \mathrm{wt} \%$.

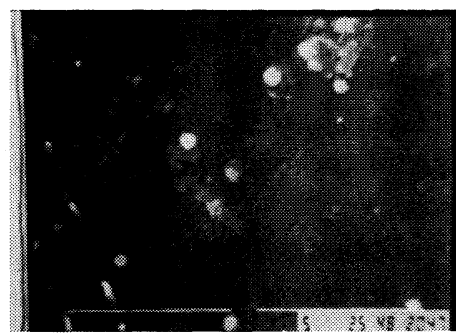

A

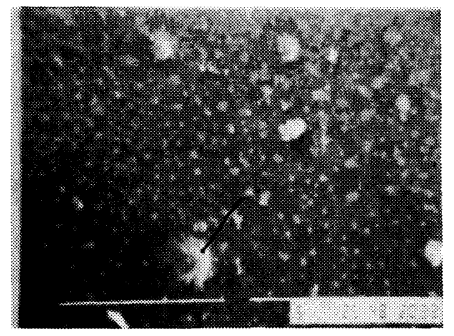

C

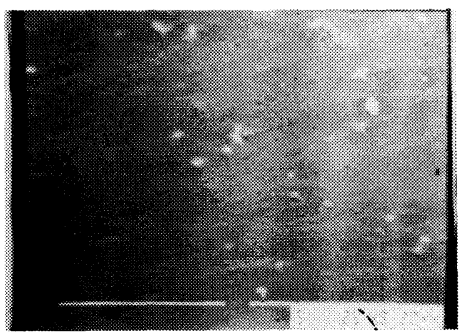

B

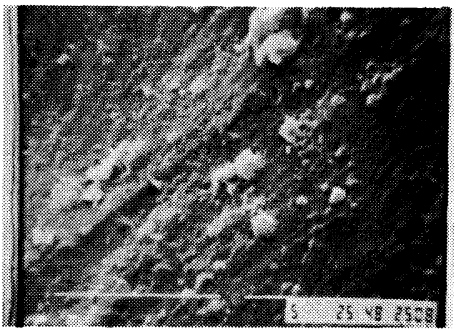

D

\section{$5 \mu \mathrm{m}$}

Figure 14. Scanning electron micrographs of TGAP/DAP/MPEI-90 system as a function of MPEI concentration: (A) $1.25 \mathrm{wt} \%$; (B) $2.5 \mathrm{wt} \%$; (C) $5.0 \mathrm{wt} \%$; (D) $10.0 \mathrm{wt} \%$.

Figures 13-15. Chemical modification time of PEI varies from $30 \mathrm{~min}$ to $180 \mathrm{~min}$. Figure 13 shows the fractured surface of MPEI/epoxy resin system at $30 \mathrm{~min}$ of treatment time. Phase separation of dispersed PEI occurs within the cured epoxy resin at the low concentration of 


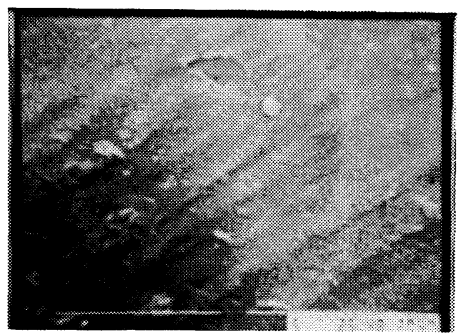

A

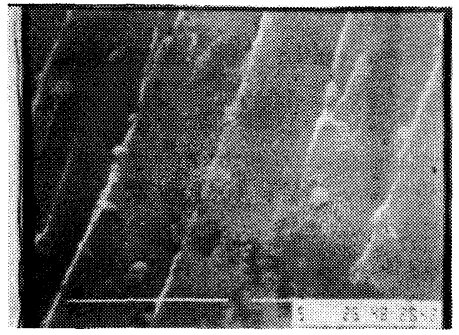

C

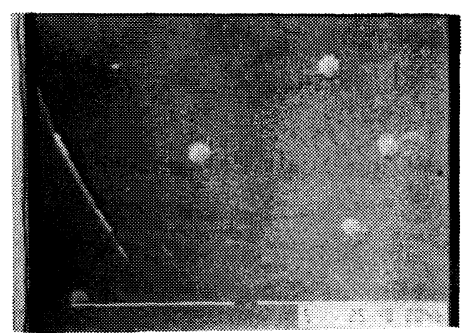

B

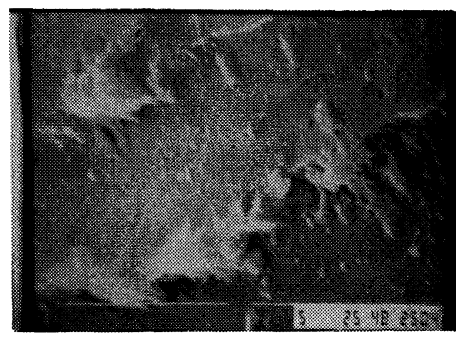

D

$5 \mu \mathrm{m}$

Figure 15. Scanning electron micrographs of TGAP/DAP/MPEI-180 system as a function of MPEI concentration: (A) $1.25 \mathrm{wt} \%$; (B) $2.5 \mathrm{wt} \%$; (C) $5.0 \mathrm{wt} \%$; (D) $10.0 \mathrm{wt} \%$.

MPEI. It was speculated that there are the small PEI dispersion particles resulting from the copolymerization of MPEI with the base epoxy resin. An optimum material should contain a portion of this dissolved PEI and a certain volume fraction of phase-separated PEI particles. ${ }^{43}$ Such combinations have been reported to offer the improved impact properties.

The situation shown in Figure 14 is different from that shown in Figure 13. In the particulate region, small inclusions of PEI have been observed under a scanning electron microscope. PEI addition has a major effect in increasing the critical deformation zone. Furthermore, because the particles are formed by essentially a precipitation process during curing reaction, it is reasonable to expect that the boundary between particle and matrix is diffuse and thus, under stress, becomes a highly plasticized region such that shear deformation dominates and inhibits microcrack initiation and propagation. ${ }^{44}$

As MPEI concentration increases up to $10 \%$ by weight, the particle diameter of dipersed particulate region increases drastically. Com- pared with UPEI/epoxy system, phase separation of MPEI within epoxy resin reduces and fractured surface of cured epoxy resin does not show the interfacial failure. New formed functional groups of PEI due to the hydrolysis react with epoxy resin and form the chemical bonding between hydrolyzed PEI and epoxy resin during curing reactions. These chemical bondings can improve the interfacial adhesion of MPEI/epoxy system.

As the chemical treatment time increases up to $90 \mathrm{~min}$, the amount of dispersed PEI drastically decreases within continuous phase. At the same concentration of PEI, the size of dispersed particulate also decreases tremendously. When the modified PEI added to tetrafunctional epoxy resin before the curing reaction, some of modified PEI can react with epoxy resin during curing reaction and form a dispersion of small particles in the continuous matrix phase. As the degree of PEI modification increases with increasing the chemical treatment time, some of modified PEI, which reacted with epoxy resin, exist in continuous phase due to the chemical bonding with epoxy 
resin. The remaining amount of MPEI can form a dispersion of PEI particle above the critical concentration of MPEI.

These phenomena conspicuously come into existence at $180 \mathrm{~min}$ of chemical treatment time. Figure 15 shows the scanning electron micrographs of fractured surface at $180 \mathrm{~min}$ of PEI treatment time. At the low concentration of MPEI, fractured surface does not show the large amount of dispersed PEI. Compared with fractured surface at $30 \mathrm{~min}$ of treatment the number and size of dispersed PEI particle reduced significantly at 2.5 and $5.0 \%$ by weight of PEI concentration.

Judging from the morphological consideration, fracture toughness of cured epoxy system is strongly dependent on the morphology change of MPEI/epoxy system. MPEI/epoxy system at $30 \mathrm{~min}$ of treatment time shows the highest fracture toughness and this is due to the degree for phase separation and chemical bonding between MPEI and epoxy resin. At the low concentration of MPEI, MPEI/epoxy system at $180 \mathrm{~min}$ shows less phase separated that at $30 \mathrm{~min}$. Just as the fracture properties of cured epoxy resin are dramatically changed by the addition of PEI, the mechanical properties of the modified resins are also affected and become different from those of the unmodified epoxy resin.

\section{REFERENCES}

1. C. E. Browning, Polym. Eng. Sci., 18, 16 (1978).

2. E. L. McKangue, J. D. Reynold, and J. E. Haskin, J. Appl. Polym. Sci., 22, 1643 (1978).

3. A. Apicella, L. Nicolais, G. Astarita, and E. Drioli, Polymer, 20, 1143 (1979).

4. J. Mijovic, J. Kim, and J. Slaby, J. Appl. Polym. Sci., 29, 144 (1984).

5. A. F. Yee and R. A. Pearson, "Toughening Mechanism in Elastomer Modified Epoxy Resins," NASACR-3718 (1983) and NASA-3852 (1984).

6. A. V. Pocius, W. J. Schultz, and R. E. Adam, "The Proceedings of the Adhesion Society," Washington, D.C., 1986, p 4.

7. L. T. Manzione and J. K. Gillham, J. Appl. Polym. Sci., 26, 889 (1981).

8. L. T. Manzione and J. K. Gillham, J. Appl. Polym.
Sci., 26, 907 (1981).

9. H. N. Nae, S. Reich, and Z. Nir, "Rubber-Modified Thermoset Resins," American Chemical Society, Washington, D.C., 1984, p 218.

10. R. S. Bauer, The Proceedings of 18 th International SAMPE Technical Conference, October 7-9, 1986, pp $510-519$.

11. L. C. Chan, J. K. Gillham, A. J. Kinlock, and S. J. Shaw, "Rubber-Modified Thermoset Resins," American Chemical Society, Washington, D.C., 1984, p 261.

12. S. Henry and Y. Hsich, The Proceedings of 34th International SAMPE Symposium, May 8-11, 1989, p 884.

13. H. Younhing, W. Huigong, and Z. Xiping, The Proceedings of 34th International SAMPE Symposium, May 8-11, 1989, p 875.

14. B. L. Riley, V8/GR. MK5 Air Frame Composite Application, in Proceedings of the 2nd International Conference on Fiber Reinforced Composites, London Institute of Mechanical Engineering, Publication C33/86, 1986, p 153.

15. R. S. Rayhava, The Proceedings of 28th National SAMPE Conference, Vol. 28, 1983, p 367.

16. R. S. Bauer, A. G. Filippov, L. M. Sclandt, and W. V. Breitigana, The Proceedings of 32nd International SAMPE Symposium, April 6-9, 1987, pp 1104 1113.

17. R. S. Bauer, "The Proceedings of 33rd International SAMPE Symposium," March 7-10, 1988, pp 1385-1393.

18. R. S. Bauer, "The Proceedings of 34th International SAMPE Symposium," May 7-11, 1989, pp 1889 1900.

19. L. M. Schlaudt, R. S. Bauer, and C. A. Blackburn, "The Proceedings of 34th International SAMPE Symposium," May 8-11, 1989, pp 917-928.

20. J. S. Shim, W. Lee, and J. Jang, Polym. J., 23, 903 (1991).

21. J. S. Shim, W. Lee, and J. Jang, Polym. J., 23, 911 (1991).

22. J. S. Shim, W. Lee, and J. Jang, Polym. Bull., 25, 661 (1991).

23. J. S. Shim, W. Lee, and J. Jang, Polym. Bull., 25, 669 (1991).

24. M. S. Selton, P. T. McGrail, J. A. Peacock, S. P. Wilknson, R. A. Crick, M. Davies, and G. Almen, The Proceedings of 19th International SAMPE Technical Conference, Vol. 19, 1987, p 700.

25. D. A. Shimp, F. A. Hudock, and W. S. Boho, The Proceedings of 18th International SAMPE Technical Conference, Vol. 18, 1986, p 851.

26. P. Steiner, J. M. Browne, M. T. Blain, and J. M. McKillen, The Proceedings of 18th International SAMPE Technical Conference, Vol. 18, 1986, p 851.

27. H. D. Stenzenberger, P. Koenig, M. Herzog, W. Romer, S. Pierce, and M. Canning, "The proceedings 
of 32nd International SAMPE Symposium," Vol. 32, 1987, p 44.

28. A. Okamoto, Polym. Eng. Sci., 23, 222 (1983).

29. E. M. Yokgitis, N. S. Eiss Jr., C. Tran, G. L. Wilkes, and J. E. McGrath, in "Epoxy Resins and Composites I,” K. Dusek, Ed., Springer-Verlag, Berlin, 1986, pp 79-109.

30. C. A. May, "Epoxy Resin Chemistry and Technology,” C. A. May, Ed., Marcel Dekker, Inc., New York and Basel, 1988.

31. A. R. Siebert and C. K. Riew, Paper presented at the 161st ACS Meeting, Organic Coating Plastic Division, Los Angeles, CA, 1971.

32. R. A. Pearson and A. F. Yee, Polym. Mater. Sci. Eng. Prepr., 316 (1983).

33. C. A. Finch, S. Hashemi, and A. J. Kinloch, Polym. Commun., 28, 322 (1987).

34. J. M. Barton, in "Epoxy Resins and Composites I," K. Dusek, Ed., Springer-Verlag, Berlin, 1986, pp $111-154$.

35. R. E. Fines and J. P. Bartolomucci, in "Engineering Plastics," N. J. Epel, J. M. Margolis, S. Newman, and R. B. Seymour, Ed., ASM International, New
York N.Y., 1988, pp 156-158.

36. C. B. Bucknall, "Toughened Plastics," Applied Science, London, 1977.

37. A. J. Kinloch and D. L. Hunston, J. Mater. Sci. Lett., 6, 137 (1987).

38. S. C. Kuns-Douglass, P. W. R. Beaumont, and M. F. Ashby, J. Mater. Sci., 15, 1109 (1980).

39. R. B. Bauer and H. D. Stenzenberger, "The Proceedings of 34th International SAMPE Symposium," May 8-11, 1989, p 899.

40. W. D. Bascom, R. Y. Ting, R. J. Moulton, C. K. Riew, and A. R. Siebert, J. Mater. Sci., 16, 2697 (1981).

41. M. S. Sefton, P. T. McGrail, and J. A. Peacock, "The Proceedings of 32nd International SAMPE Symposium," May, 1987, p 700.

42. A. Okamoto, Poym. Eng. Sci., 23, 222 (1983).

43. L. T. Mazione and J. K. Gillham, Paper presented at the 178th ACS National Meeting, Organic Coating Plastic Divisions, Washington, D.C., 1979.

44. C. K. Riew, E. H. Rowe, and A. R. Siebert, in "Toughness and Brittleness of Plastics," ACS Advance in Chemistry Series, 154, 326 (1976). 